\title{
Recent developments in Raman and infrared spectroscopy and imaging of bone tissue
}

\author{
Michael D. Morris* and William F. Finney \\ Department of Chemistry, University of Michigan, Ann Arbor, MI 48109, USA
}

\begin{abstract}
Vibrational spectroscopy is an important tool in mineralized tissue research. This review focuses on recent applications of Raman and IR spectroscopies as contrast enhancement agents, tools for studying the chemical nature of changes in bone tissue with age and disease and understanding the molecular nature of changes in bone tissue during mechanical loading and fracture.
\end{abstract}

\section{Introduction}

Vibrational spectroscopy is now acknowledged as an important tool for characterization of the chemical composition and physical state of bone tissue. This topic was reviewed less than four years ago [4]. Since that time interest in and the application of both infrared and Raman spectroscopy to mineralized tissue research has increased rapidly. Raman spectroscopy, the focus of this brief review, has progressed from exploratory studies to substantive applications as a tool for research into age and disease related changes in bone as well as the molecular response of bone to mechanical load.

Both Raman and infrared spectroscopy are important and complementary to each other in mineralized tissue research. Vibrational spectroscopy uniquely provides non-destructive, quantitative information simultaneously on the mineral and the protein matrix. Both IR and Raman spectroscopies are sensitive to local environmental effects, such as changes in mineral substituents or protein secondary structure. Raman spectroscopy provides superior spatial resolution and easier access to low frequency vibrations, while infrared spectroscopy offers generally better signal to noise ratios and is more widely available. Table 1 lists the major infrared and Raman bands of bone tissue, with assignments.

\section{Bone tissue specimen preparation}

Bone tissue specimens must be IR-transparent for measurement by infrared spectroscopy. In practice this means that the specimens can be no thicker than about 5-10 $\mu \mathrm{m}$ thick and must be mounted on IR-transparent slides. Attenuated total reflection spectroscopy is possible, but is rarely employed because is difficult to observe low frequency bands. For study of phosphate bending vibrations, which are very sensitive to mineral properties, synchrotron IR spectroscopy and imaging remain the techniques of choice $[11,12]$.

\footnotetext{
*Corresponding author: Tel.: +1 734764 7360; Fax: +1 734615 3790; E-mail: mdmorris@ umich.edu.
} 
Table 1

IR and Raman band assignments for bone tissue. IR bands are in parentheses

\begin{tabular}{|c|c|}
\hline Assignment & $\begin{array}{l}\text { Raman shift } \\
\text { (IR frequency) } / \mathrm{cm}^{-1}\end{array}$ \\
\hline$\overline{\mathrm{PO}_{4}^{3-} \nu_{2}}$ & $422-454(470)$ \\
\hline $\mathrm{PO}_{4}^{3-} \nu_{4}$ & $578-617(566,605)$ \\
\hline Hydroxyproline, $\nu(\mathrm{C}-\mathrm{C})$ & $855(844)$ \\
\hline Hydroxyproline, $\nu(\mathrm{C}-\mathrm{N})$ & $876(877)$ \\
\hline $\mathrm{CO}_{3}^{2-} \nu_{2}$ & $(860-890)$ \\
\hline $\mathrm{PO}_{4}^{3-} \nu_{1}$ & $857-962$ (963) \\
\hline Proline, $\nu(\mathrm{C}-\mathrm{N})$ & $921(911)$ \\
\hline $\mathrm{HPO}_{4}^{2-} \nu_{3}$ & $1003-1005$ (1145) \\
\hline Phenylalanine & 1004 (1494) \\
\hline $\mathrm{PO}_{4}^{3-} \nu_{3}$ & $1006-1055$ (1033) \\
\hline $\mathrm{CO}_{3}^{2-} \nu_{1} / \mathrm{PO}_{4}^{3-} \nu_{3}$ & $1065-1071$ \\
\hline Amide III & $1243-1320(1230-1300)$ \\
\hline$\delta\left(\mathrm{CH}_{2}\right)$, scissoring & $1447-1452$ \\
\hline Amide II & $1540-1580(1520-1620)$ \\
\hline $\mathrm{CO}_{3}^{2-} \nu_{3}$ & $(1350-1580)$ \\
\hline Amide I & $1595-1700(1630-1700)$ \\
\hline$\nu\left(\mathrm{CH}_{2}\right)$ & $2840-2986(2840-2986)$ \\
\hline Amide A & $(3303-3311)$ \\
\hline Amide B & $(3063)$ \\
\hline$\nu(\mathrm{O}-\mathrm{H})$ & $3572-3575(3572-3575)$ \\
\hline
\end{tabular}

Specimens for Raman spectroscopy can be any thickness, from as little as $5 \mu \mathrm{m}$ up to and including intact tissue, although observations are typically limited to within 20-30 $\mu \mathrm{m}$ of the surface of the specimen. Most bone Raman spectroscopy is performed with deep red or near-infrared lasers to circumvent tissue fluorescence. Hydrogen peroxide has been recommended for bleaching fluorophores to allow spectroscopy with green lasers $[9,19]$. In our hands, however, this technique has not proven robust [5]. Photobleaching in laser light is an alternative, but one which is time-consuming [20].

Histological stains are innocuous in Raman spectroscopy, if they do not absorb laser light. Most stains are present as a superficial overlay and are not observed or just barely detectable by Raman spectroscopy. Because most bone tissue Raman spectra are excited with deep red or near-infrared lasers, blue stains may strongly absorb laser light and cause local heating and damage to specimens. We have shown that some hematoxylin and eosin (H\&E) protocols result in deposition of sufficient hematoxylin to cause local heating and damage to delicate tissue if a $785 \mathrm{~nm}$ laser is used [7]. The problem can be circumvented by shorter exposure to the stain or if necessary by substitution of toluidine blue for hematoxylin.

For almost 100 years bone biologists have relied upon von Kossa staining to detect the present of apatitic mineral in their specimens. In von Kossa staining, a water soluble silver salt is added to the specimen to form silver phosphate, which is then photochemically reduced to silver metal, whose characteristic black color indicates the presence of bone mineral. Von Kossa staining is not specific for apatitic mineral and is subject to interferences from any residual buffer phosphate or halide (chloride, fluoride, etc.) present in a specimen. Infrared and Raman spectroscopy easily overcome these problems. Either technique can readily distinguish apatitic phosphate from the phosphate salts found in buffers. The problem is especially severe in cell cultures, where small (or even large) amounts of inorganic 
phosphates may be formed, only to be mis-identified by staining [21]. Cell culture artifacts have been investigated in detail by Bonewald et al. who recommend FTIR and other physical techniques such as $\mathrm{X}$-ray diffraction or electron microscopy in place of von Kossa staining [2].

\section{Mineralization studies}

The progress of mineral deposition in murine calvaria (skull tissue) has been followed from the earliest deposition in fetal tissue (about 4 days prenatal) until near maturity [16,22]. The first deposited apatitic mineral is a carbonated apatite. Prior to birth, the mineral to matrix ratio increases, but there is no change in the amount of carbonate incorporated in the mineral. The amount of incorporated carbonate in the mineral only begins to increase beginning about three days post-natal. Although the authors do not emphasize it, careful inspection of the amide I envelope shows that it differs from the amide I profile in mature tissue. In particular, the relative intensity of the $1685 \mathrm{~cm}^{-1}$ region is greater with respect to the $1670 \mathrm{~cm}^{-1}$ band in the perinatal than in mature tissue. This change in relative intensity is indicative of the relative paucity of interfibril cross-links in the newly formed matrix as compared to mature matrix. From FTIR studies it is known that amide I can report on the state of these cross-links. An increase in the intensity of the $1685 \mathrm{~cm}^{-1}$ band relative to the $1670 \mathrm{~cm}^{-1}$ indicates a greater percentage of immature interfibril cross-links relative to mature pyridinoline cross-lines [17].

A different behavior is observed in fully mature human cortical tissue [1]. Specimens of unremodeled primary bone tissue from male decedents age 17-40 show decreasing carbonate/phosphate ratio with increasing age. The ratio remains constant or increases slightly with age from about 45 to about 70 years old. These results are in accord with generally accepted views, and represent the first Raman spectroscopic study of bone tissue across the adult life span.

Study of abnormal tissue mineralization is a promising application of vibrational spectroscopy. Although incorporation of a small amount of fluoride into bone mineral is not a pathological condition, it does perturb the crystal structure measurably. Fluoridation increases mineral crystallinity, as measured by a decrease in band width and increases the frequency of the phosphate $\nu_{1}$ band [8]. The frequency shift occurs because fluoride occupies a position that is probably vacant or occupied by a water molecule in the carbonated apatite. Fluoridation causes an increase in bone ductility, although the reasons for this are not yet clear.

Infrared imaging has revealed new information about osteoporotic tissue. In osteoporotic tissue the mineral to matrix ratio is unusually low and the remaining mineral is more crystalline than in normal mature tissue [10]. Ovarectomized cynomolgus monkeys, a common model for osteoporosis, treated with recombinant human parathyroid hormone show evidence for extensive new tissue formation. Tissue on the cortical periosteal and endosteal surfaces contains matrix with fewer cross-links than normal tissue and mineral that is less crystalline than in mature tissue [18]. From these and other studies it is clear that vibrational spectroscopy and imaging will play an important role in the study of osteoporosis.

Craniosynostosis is the first bone disease that has been studied by Raman spectroscopy. In craniosynostosis premature fusion of the calvaria occurs. The condition may have either genetic or mechanical causes and is treatable only by surgery. Using Raman imaging, our group has shown that placement of beads doped with fibroblast growth factor 2 (FGF2) in the cranial sutures tissue excised from 18 day fetal mice leads to premature mineralization [6]. Abnormal expression of FGF2 is thought to be one of the genetic causes of craniosynostosis. The induced mineral and matrix are spectroscopically indistinguishable from normally deposited tissue at the same stage of mineralization. Similarly, we have shown 
that the suture mineralization induced by periodic compression of calvarial tissue is normal, although premature [15].

\section{Biomechanical studies}

Bone is a structural material in and its mechanical properties are central to understanding its normal function and traumatic failure. Bone tissue is subject to minor failure (microcracking) under ordinary mechanical stresses. Damaged tissue is resorbed and new tissue formed, a process called remodeling. In early studies our group demonstrated that the bone mineral spectrum at the periphery of a microcack was different from that of adjacent tissue [23]. Whether the difference arose from local (presumably weaker) tissue composition or were a consequence of cracking could not be established. Similar changes were observed in murine femoral cortical tissue that had been fractured [13]. The cause/effect conundrum has been settled by indentation studies that demonstrate changes in bone mineral crystal structure inside indents compared to immediately outside [3]. Indentation also shows shearing failure of collagen interfibril cross-links at the perimeter of and indent, but not in its center, explaining one source of the well-known weakness of bone under shear. In the elastic deformation regime reversible changes are observed.

Classically, bone mineral is viewed as mechanically inert and contributing only mass and stiffness to the mechanical properties of bone tissue. It is becoming clearer that such a model is a first approximation and must be modified to account for dynamic changes. Lattice deformation can be observed as a shift in the center of gravity of the phosphate $\nu_{1}$ band envelope under elastic and clearly physiological conditions [14]. While it is not surprising that new mineral species can be observed when a bone is subjected to destructive or clearly plastic deformation, changes observed in the elastic deformation regime suggest that the bone mineral plays a more active role in the mechanical properties of bone tissue than is generally appreciated.

\section{Acknowledgement}

Supported in part by NIH grant R01 AR047969 to M.D.M.

\section{References}

[1] O. Akkus, A. Polyakova-Akkus, F. Adar and M.B. Schaffler, Aging of microsctructural compartments in human compact bone, J. Bone Miner. Res. 18 (2003), 1012-1019.

[2] L.F. Bonewald, S.E. Harris, J. Rosser, M.R. Dallas, S.L. Dallas, N.P. Camacho, B. Boyan and A. Boskey, Von Kossa staining alone is not sufficient to confirm that mineralization in vitro represents bone formation, Calcif. Tiss. Int. 72 (2003), 537-547.

[3] A. Carden, R.M. Rajachar, D.H. Kohn and M.D. Morris, Ultrastructural changes accompanying the mechanical deformation of bone tissue: A Raman imaging study, Calcif. Tiss. Int. 72 (2003), 166-175.

[4] A. Carden and M.D. Morris, Application of vibrational spectroscopy to the study of mineralized tissues, J. Biomed. Optics 5 (2000), 259-268.

[5] T.-C. Chen, D.A. Shea and M.D. Morris, Effect of hydrogen peroxide bleaching on bone mineral/matrix ratio, Appl. Spectrosc. 56 (2002), 1035-1037.

[6] N.J. Crane, W. Wang, M.A. Ignezi, Jr. and M.D. Morris, Spectral imaging of mouse skulls undergoing craniosynostosis, Proc. SPIE 4959 (2003), 111-120.

[7] N.J. Crane, L.E. Gomez, M.A. Ignelzi, Jr. and M.D. Morris, Compatibility of histological staining protocols for bone tissue with Raman microspectroscopy and imaging, Calcif. Tiss. Int. in press. 
[8] J.J. Freeman, B. Wopenka, M.J. Silva and J.D. Pasteris, Raman spectroscopic detection of changes in bioapatite in mouse femora as a function of age and in vitro fluoride treatment, Calcif. Tiss. Int. 68 (2001), 156-162.

[9] J.J. Freeman and M.J. Silva, Separation of the Raman spectral signatures of bioapatite and collagen in compact mouse bone bleached with hydrogen peroxide, Appl. Spectrosc. 56 (2002), 770-775.

[10] R. Mendelsohn, E.P. Paschalis, P.J. Sherman and A.L. Boskey, IR microscopic imaging of pathological states and fracture healing of bone, Appl. Spectrosc. 54 (2000), 1183-1191.

[11] L.M. Miller, J. Tibrewala and C.S. Carlson, Examination of bone chemical composition in osteoporosis using fluorescence-assisted syncrhotron infrared microspectroscopy, Cell. Mol. Biol. 46 (2000), 1035-1044.

[12] L.M. Miller, V. Vairavamurthy, M.R. Chance, R. Mendelsohn, E.P. Paschalis, F. Betts and A.L. Boskey, In situ analysis of mineral content and crystallinity in bone using infrared micro-spectroscopy of the $\nu_{4} \mathrm{PO}_{4}^{-3}$ vibration, Biochim. Biophys. Acta 1527 (2001), 11-19.

[13] M.D. Morris, D.A. Carden, R.M. Rajachar and D.H. Kohn, Effects of applied load on bone tissue as observed by Raman spectroscopy, Proc. SPIE 4614 (2002), 47-54.

[14] M.D. Morris and W.F. Finney, Bone tissue ultrastructural response to eleastic deformation probed by Raman spectroscopy, Chem. Soc. Faraday Discuss. 126 (2003), in press.

[15] M.D. Morris, S. Stewart, C.P. Tarnowski, D. Shea, R. Franceschi, D. Wang, M.A. Ignelzi, W. Wang, E.T. Keller, D.L. Lin, S.A. Goldstein and J.M. Taboas, Early mineralization of normal and pathologic calvaria as revealed by Raman spectroscopy, Proc. SPIE 4614 (2002), 28-39.

[16] M.D. Morris, C.P. Tarnowski, J.L. Dreier and M.A. Ignelzi, Raman microscopy of de-novo woven bone tissue, Proc. SPIE 4254 (2001), 90-96.

[17] E.P. Paschalis, K. Verdelis, S.B. Doty, A.L. Boskey, R. Mendelsohn and M. Mamauchi, Spectroscopic characterization of collagen cross-links in bone, J. Bone Miner. Res. 16 (2001), 1821-1828.

[18] E.P. Paschalis, D.B. Burr, R. Mendelsohn, J.M. Hock and A.L. Boskey, Bone mineral and collagen quality in humeri of ovariectomized cynomolgus monkeys given rhPTH(1-34) for 18 months, J. Bone Miner. Res. 18 (2003), 769-775.

[19] G. Penel, G. Leroy and E. Bres, New sample method of bone samples for Raman microspectrometry, Appl. Spectrosc. 52 (1998), 312-313.

[20] D. Shea and M.D. Morris, Bone tissue fluorescence reduction for visible laser Raman spectroscopy, Appl. Spectcrosc. 56 (2002), 182-185.

[21] S. Stewart, D.A. Shea, C.P. Tarnowski, M.D. Morris, D. Wang, R. Franceschi, D.-L. Lin and E. Keller, Trends in early mineralization of murine calvarial osteoblastic cultures: A Raman microscopic study, J. Raman Spectrosc. 33 (2002), 536-543.

[22] C.P. Tarnowski, M.A. Ignelzi, Jr. and M.D. Morris, Mineralization of developing mouse calvaria as revealed by Raman microspectroscopy, J. Bone Miner. Res. 17 (2002), 1118-1126.

[23] J.A. Timlin, A. Carden, M.D. Morris, R.M. Rajachar and D.H. Kohn, Raman spectroscopic imaging markers for fatiguerelated microdamage in bovine bone, Anal. Chem. 72 (2000), 2229-2236. 


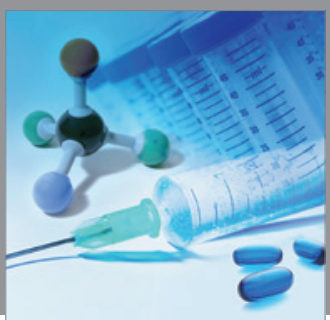

International Journal of

Medicinal Chemistry

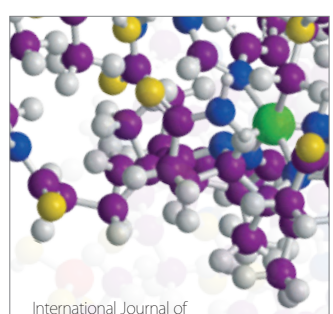

Carbohydrate Chemistry

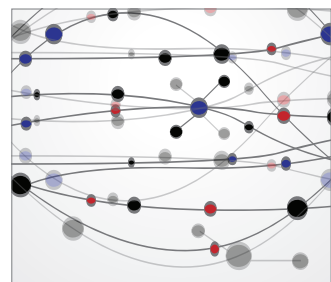

The Scientific World Journal
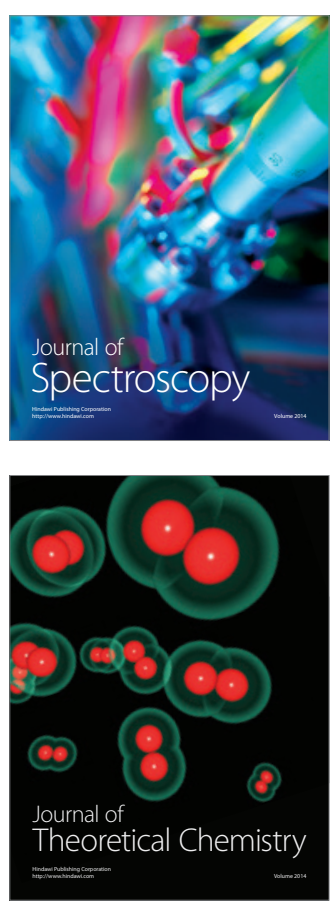
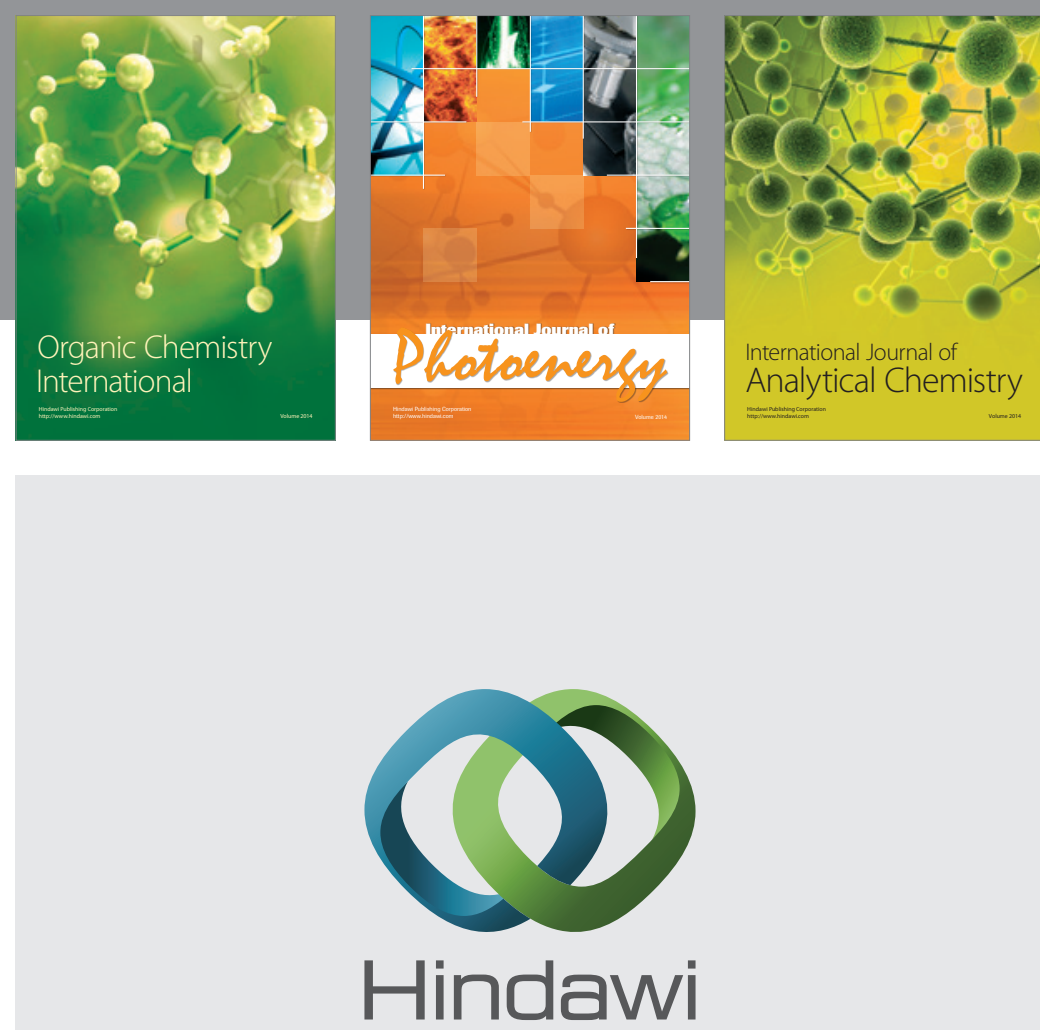

Submit your manuscripts at

http://www.hindawi.com
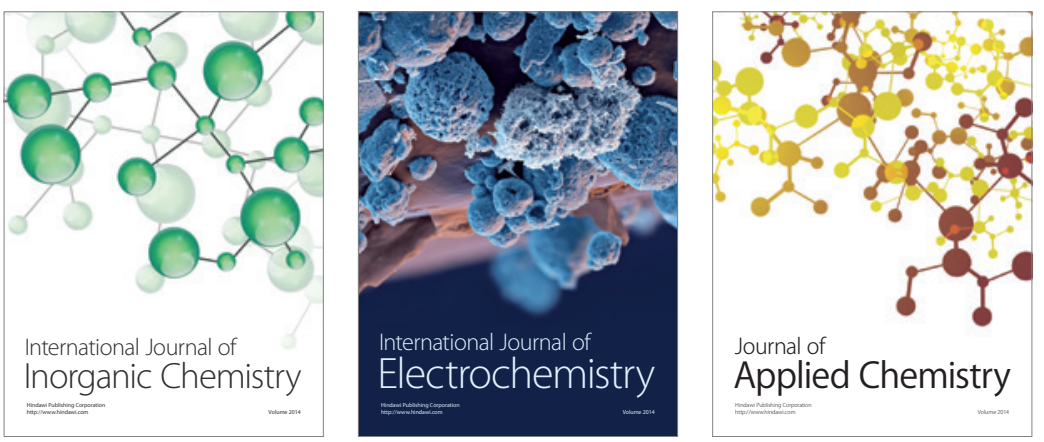

Journal of

Applied Chemistry
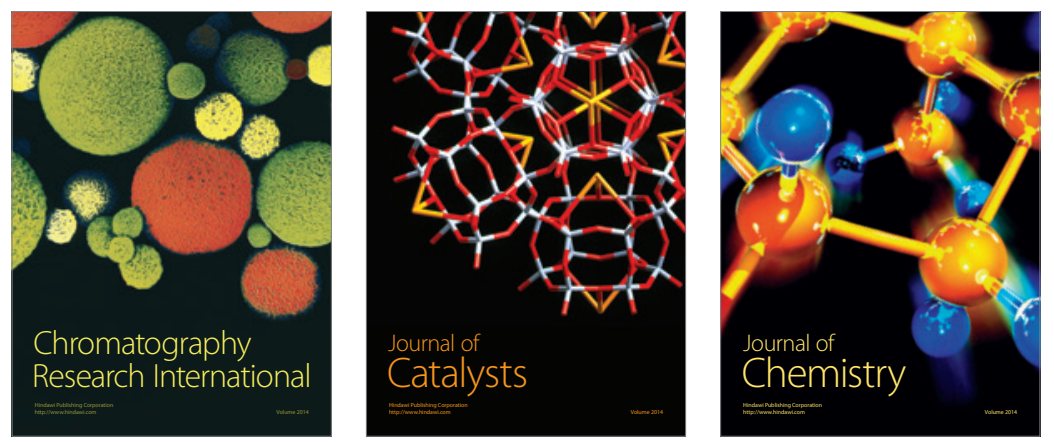
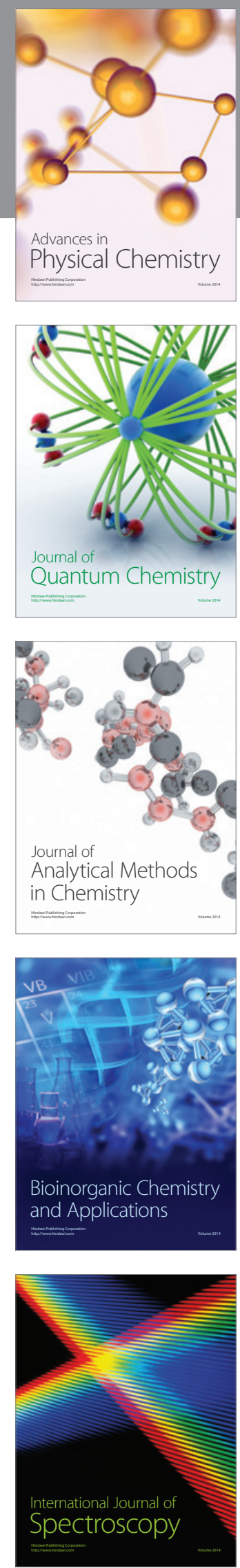